\title{
Isothermal nanocalorimetry of isotactic polypropylene
}

\author{
Felice De Santis, ${ }^{*}{ }^{\dagger}$ Sergey Adamovsky, ${ }^{\star}$ Giuseppe Titomanlio, ${ }^{\dagger}$ Christoph Schick ${ }^{\ddagger}$ \\ ${ }^{\dagger}$ Department of Chemical and Food Engineering, University of Salerno, 84084 Fisciano (SA), Italy; \\ Institute of Physics, University of Rostock, 18051 Rostock, Germany
}

*CORRESPONDING AUTHOR E-mail: fedesantis@unisa.it

The figures showing all the results: experimental temperature evolution of isotherm performed at each set temperature (Figures S1-S17). 


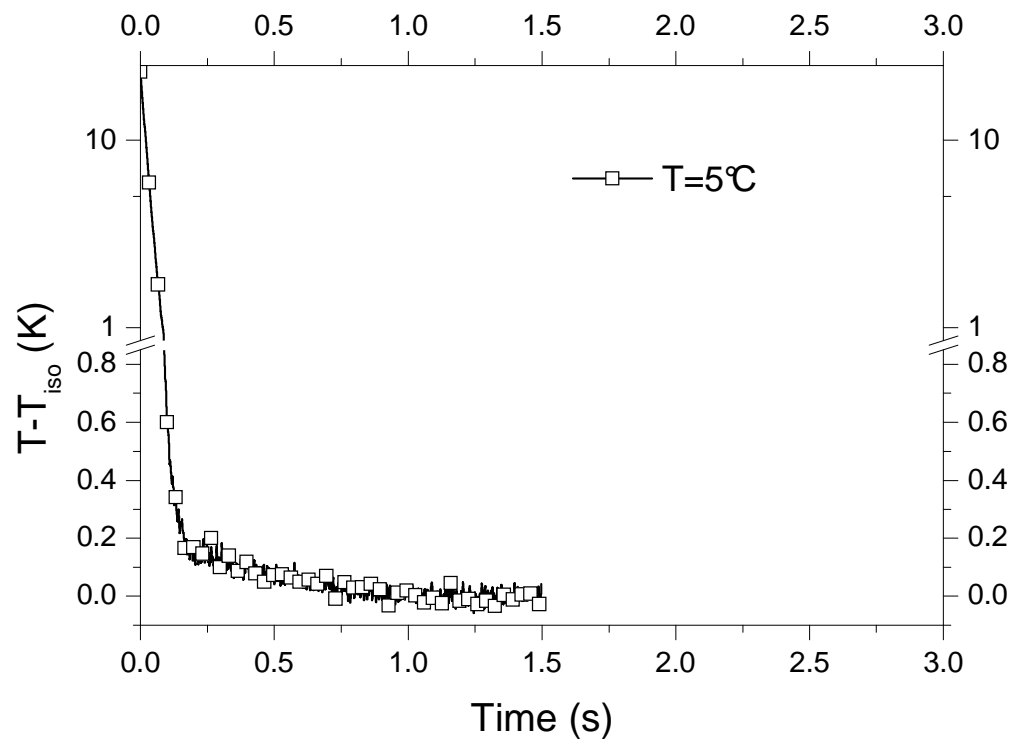

Figure S1. Experimental temperature evolution of isotherm performed at set temperature of $5{ }^{\circ} \mathrm{C}$.

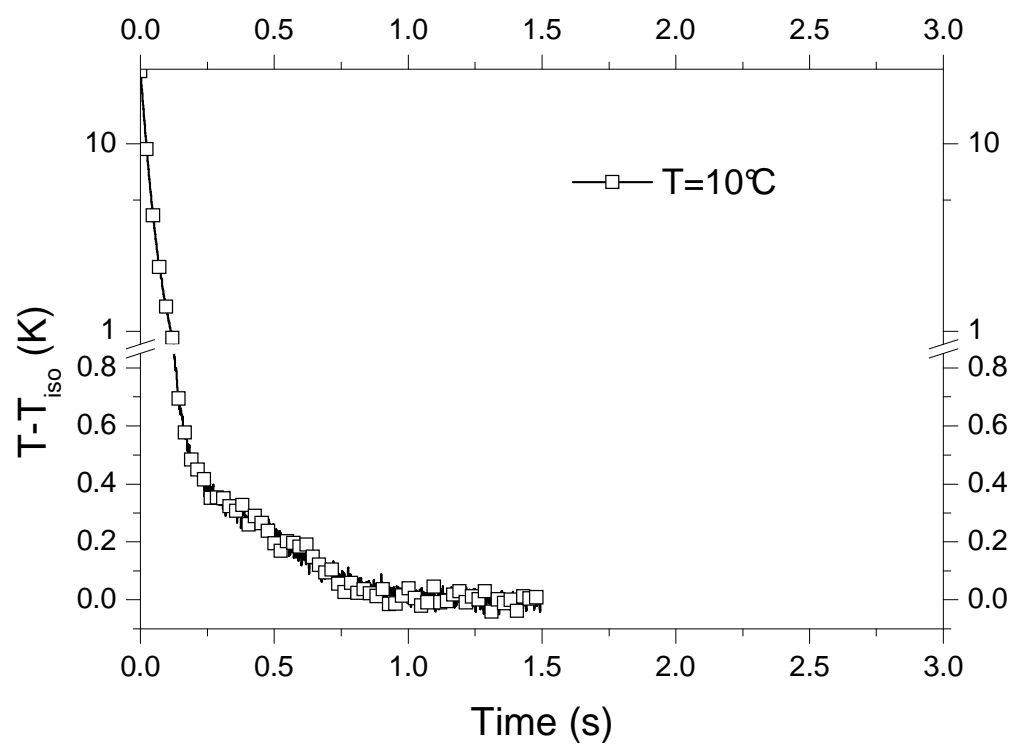

Figure S2. Experimental temperature evolution of isotherm performed at set temperature of $10^{\circ} \mathrm{C}$. 


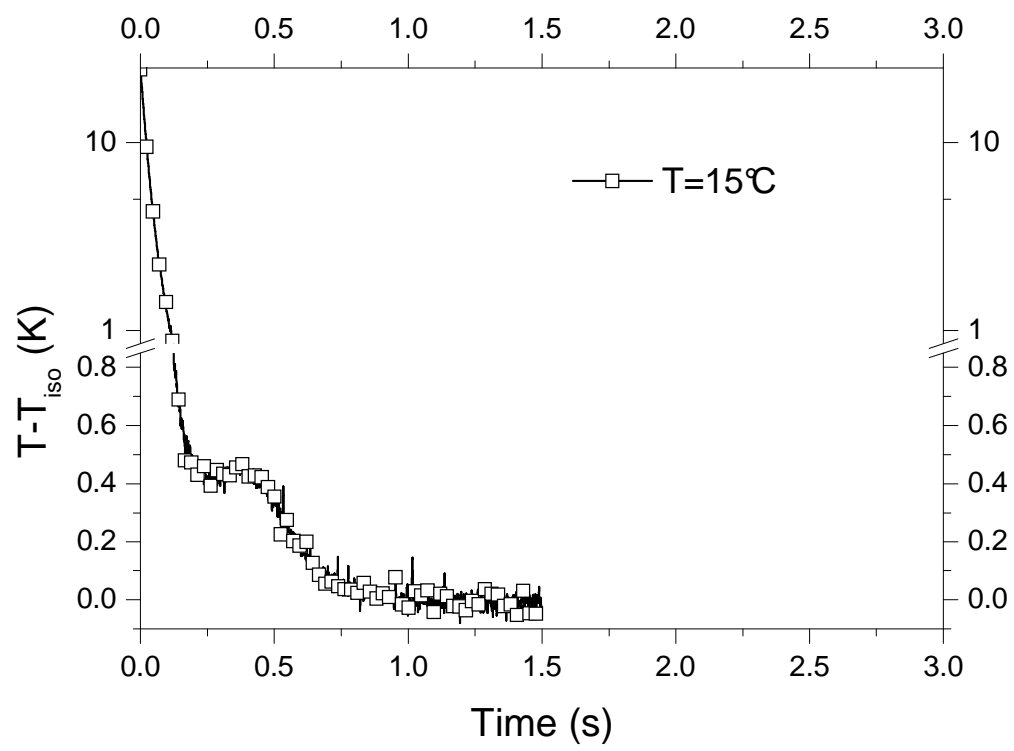

Figure S3. Experimental temperature evolution of isotherm performed at set temperature of $15^{\circ} \mathrm{C}$.

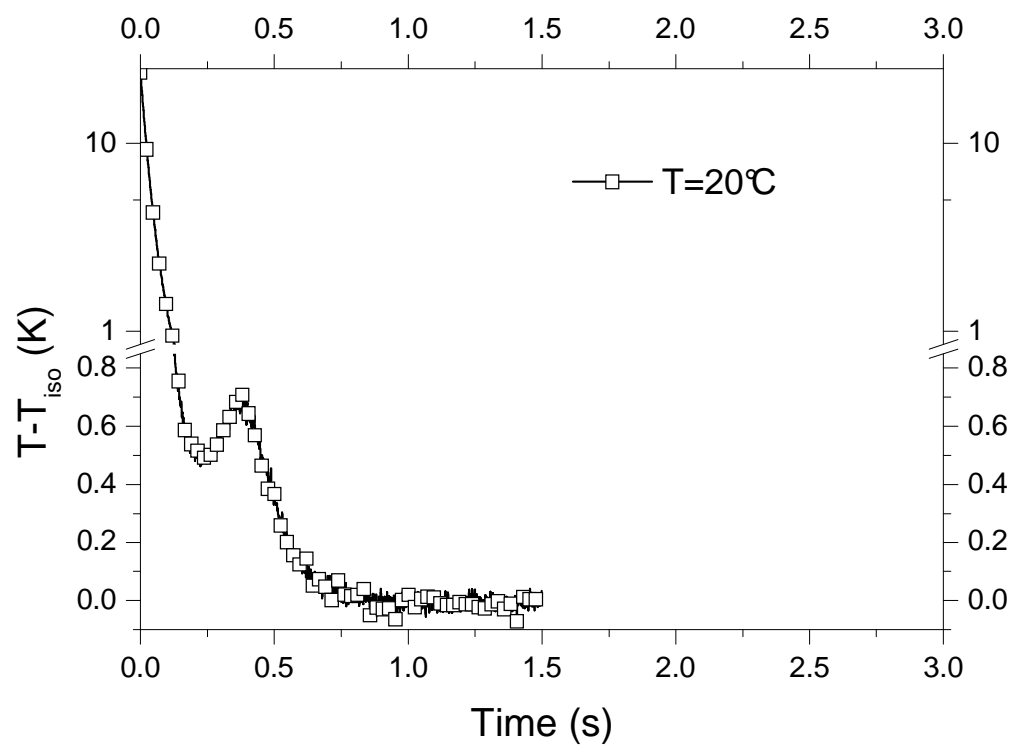

Figure S4. Experimental temperature evolution of isotherm performed at set temperature of $20{ }^{\circ} \mathrm{C}$. 




Figure S5. Experimental temperature evolution of isotherm performed at set temperature of $25^{\circ} \mathrm{C}$.

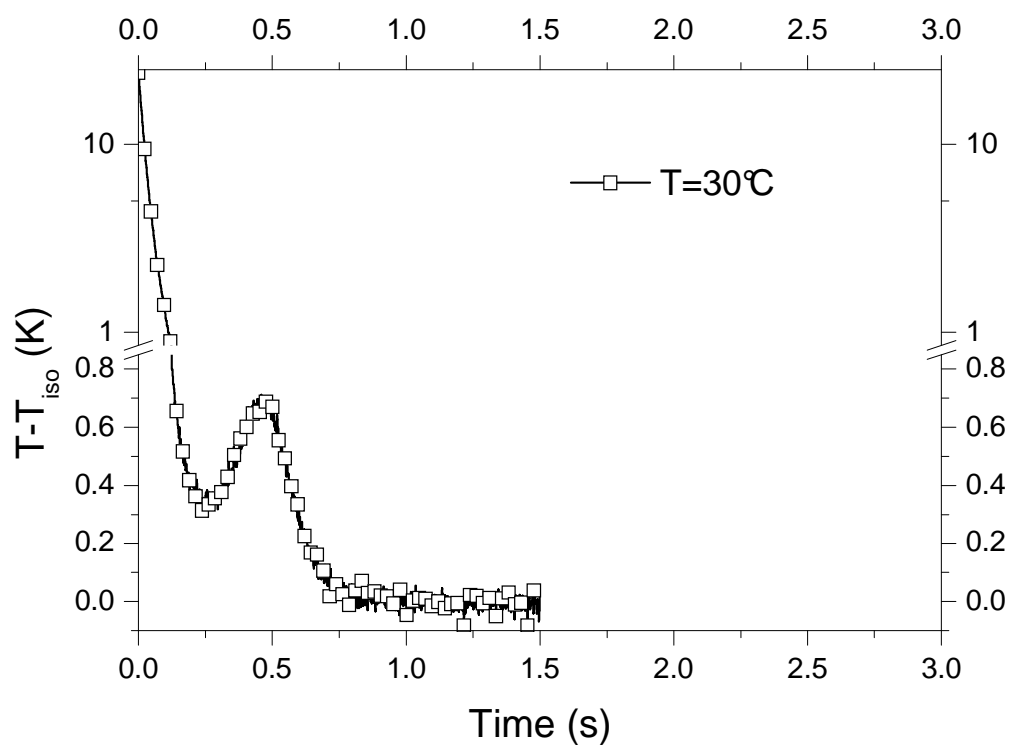

Figure S6. Experimental temperature evolution of isotherm performed at set temperature of $30{ }^{\circ} \mathrm{C}$. 


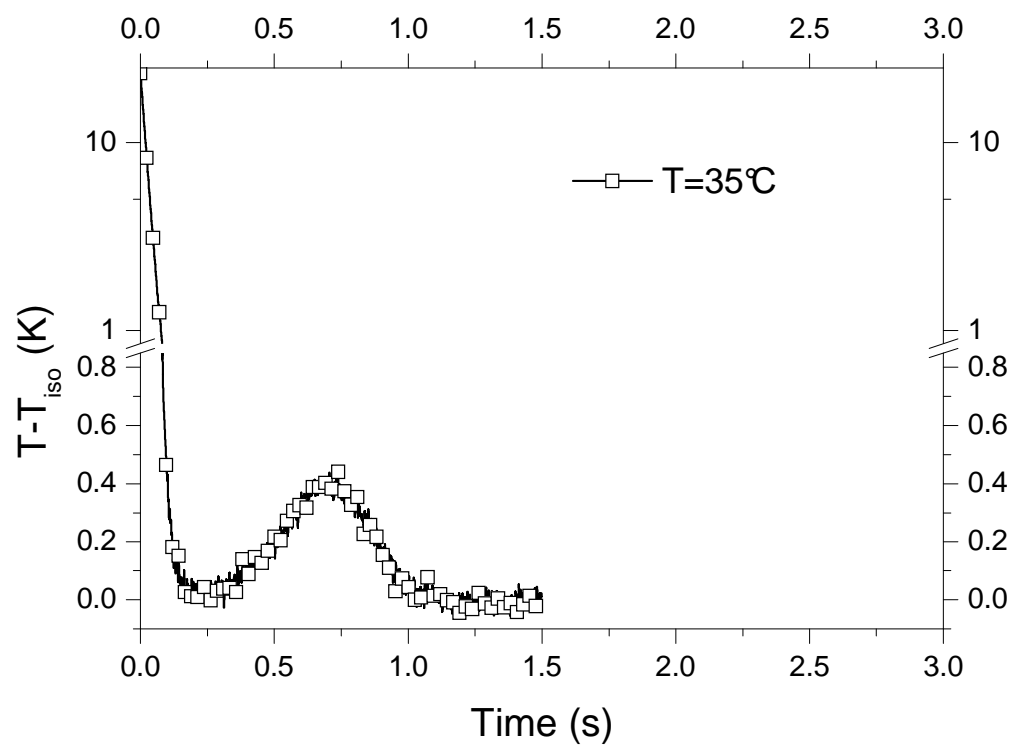

Figure S7. Experimental temperature evolution of isotherm performed at set temperature of $35^{\circ} \mathrm{C}$.



Figure S8. Experimental temperature evolution of isotherm performed at temperature of $40{ }^{\circ} \mathrm{C}$. 




Figure S9. Experimental temperature evolution of isotherm performed at set temperature of $45{ }^{\circ} \mathrm{C}$.

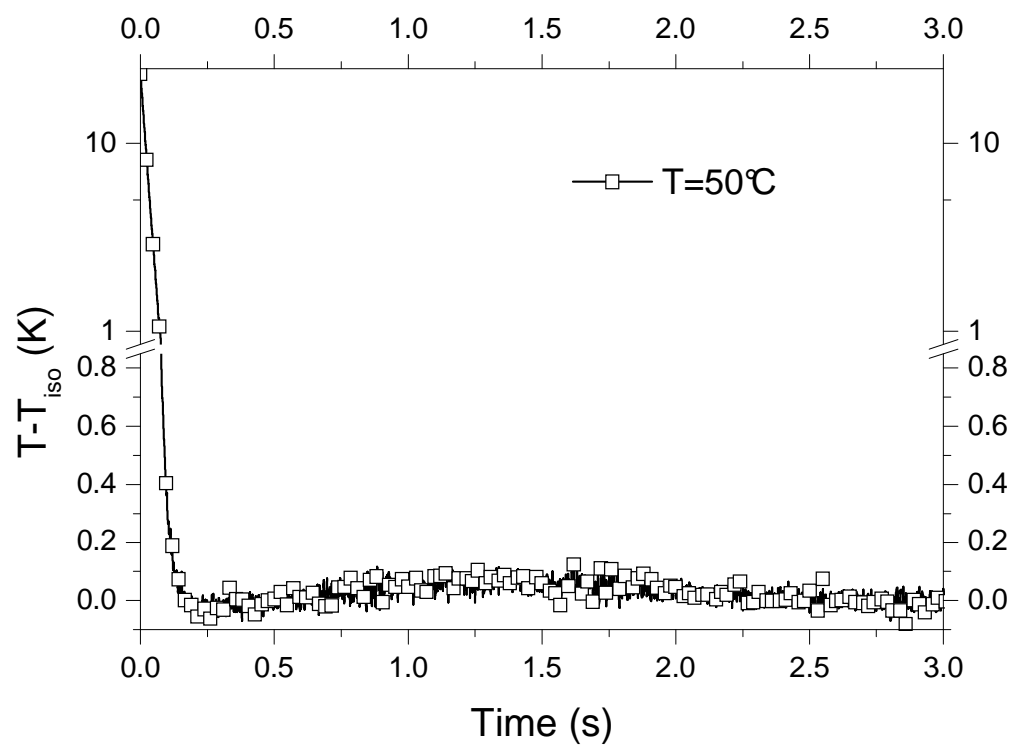

Figure S10. Experimental temperature evolution of isotherm performed at temperature of $50{ }^{\circ} \mathrm{C}$. 




Figure S11. Experimental temperature evolution of isotherm performed at set temperature of $55^{\circ} \mathrm{C}$.

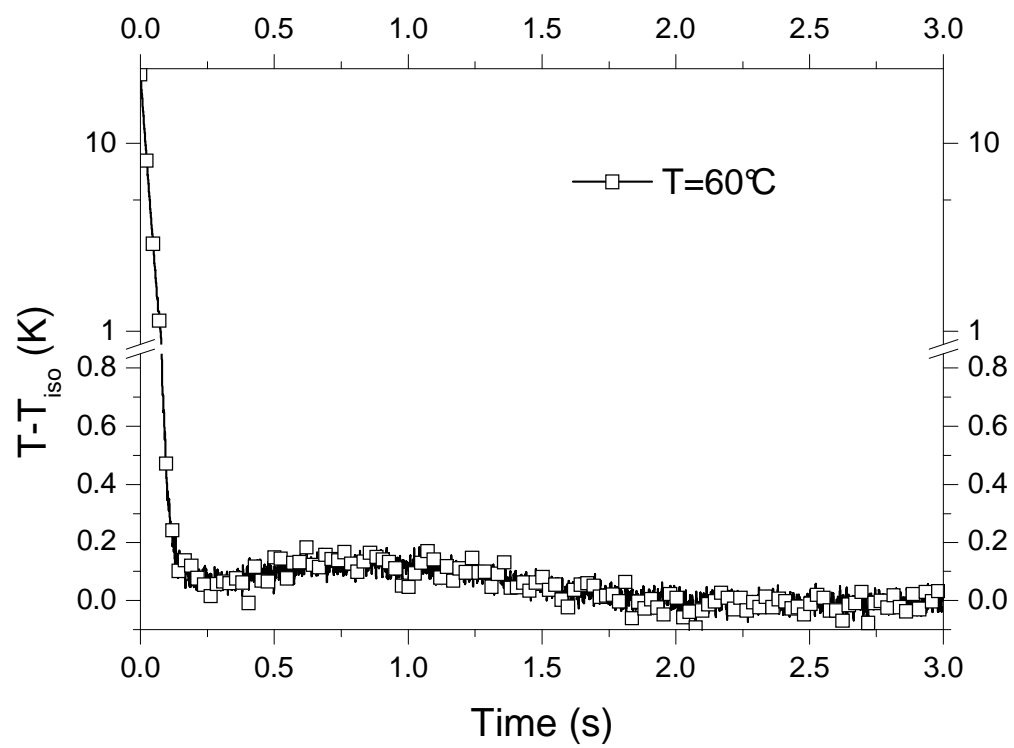

Figure S12. Experimental temperature evolution of isotherm performed at temperature of $60{ }^{\circ} \mathrm{C}$. 


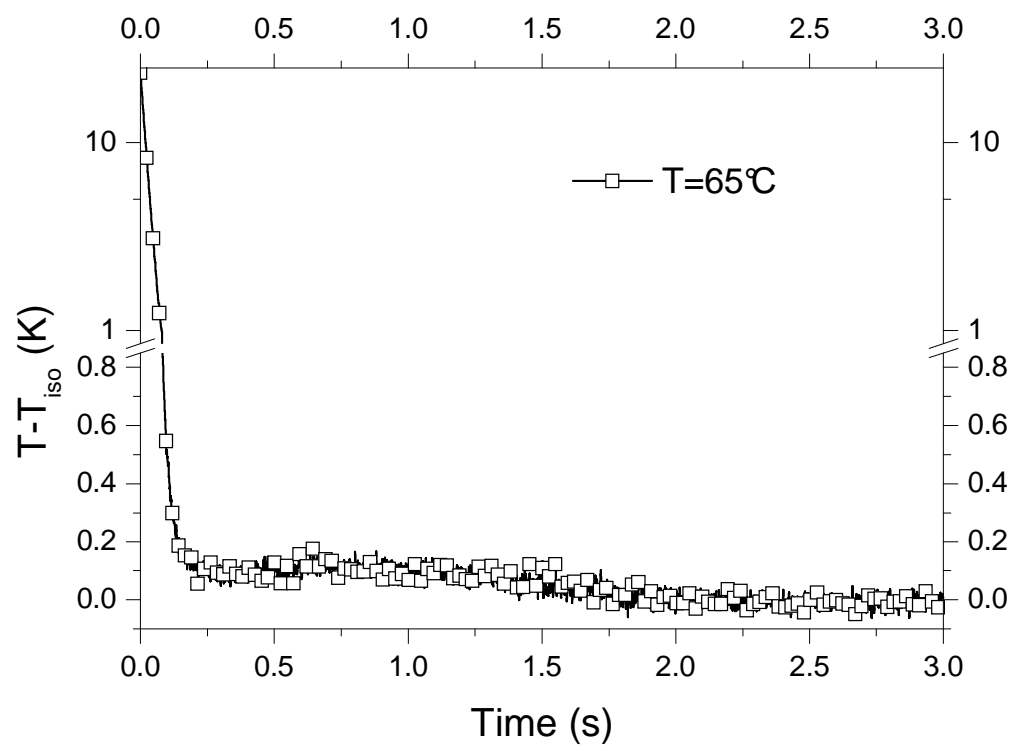

Figure S13. Experimental temperature evolution of isotherm performed at set temperature of $65^{\circ} \mathrm{C}$.

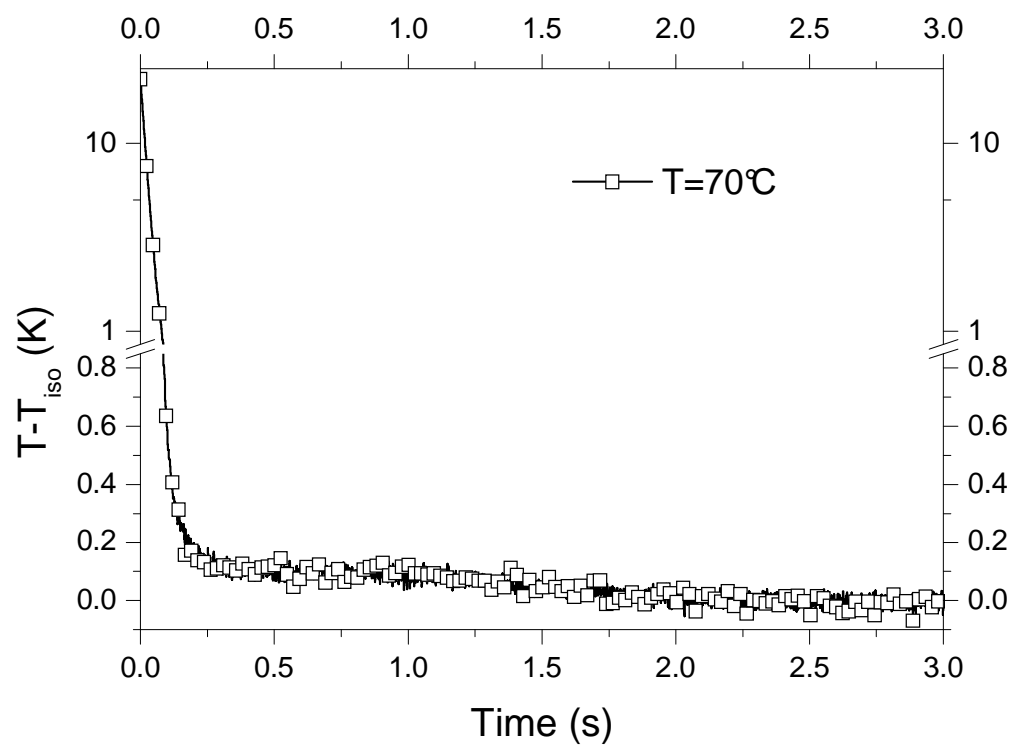

Figure S14. Experimental temperature evolution of isotherm performed at temperature of $70{ }^{\circ} \mathrm{C}$. 




Figure S15. Experimental temperature evolution of isotherm performed at set temperature of $75^{\circ} \mathrm{C}$.

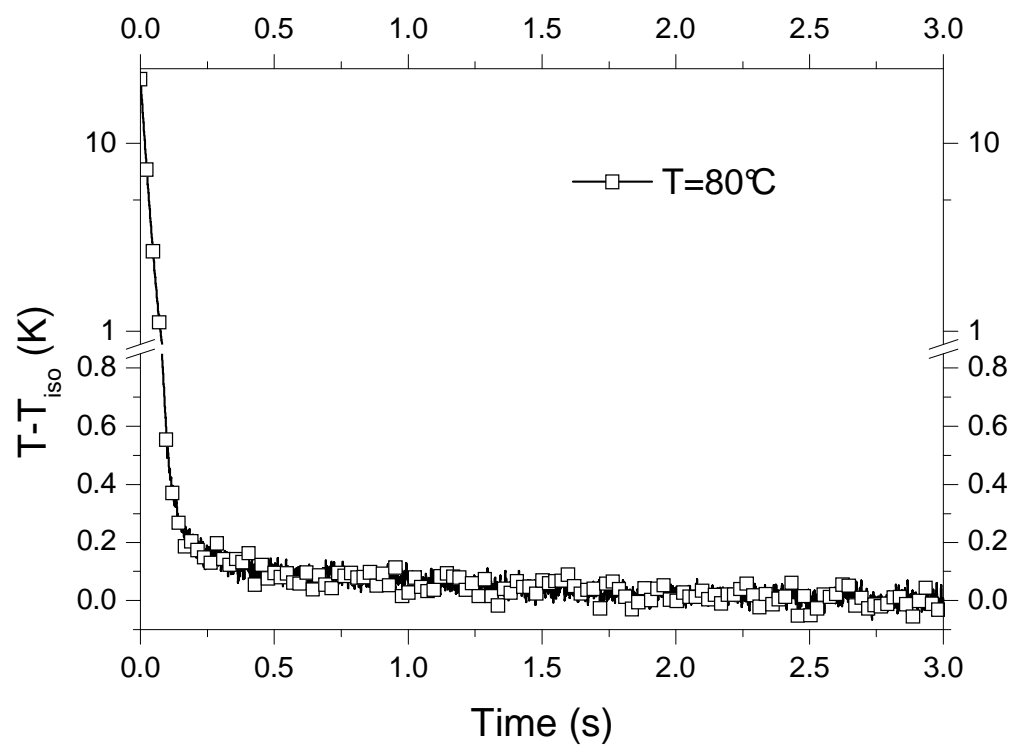

Figure S16. Experimental temperature evolution of isotherm performed at temperature of $80{ }^{\circ} \mathrm{C}$. 




Figure S17. Experimental temperature evolution of isotherm performed at set temperature of $85{ }^{\circ} \mathrm{C}$. 